\title{
Eficiência de Utilização de Nutrientes em Novilhas das Raças Canchim e Nelore e Cruzadas Canchim-Nelore
}

\author{
Airton Manzano ${ }^{1}$, Sérgio Novita Esteves ${ }^{1}$, Alfredo Ribeiro de Freitas ${ }^{1,2}$, Marco Aurélio Romano ${ }^{3}$, \\ Nelson José Novaes ${ }^{1}$
}

\begin{abstract}
RESUMO - O objetivo deste trabalho foi estudar a eficiência de utilização de nutrientes por novilhas em crescimento das raças Canchim (CA) e Nelore (NE) e 1/2 Canchim + 1/2 Nelore (CANE) em três dietas: mantença, relação volumoso:concentrado: (RVC) de 75:25 (Teste 1); dieta para ganhos de 700 g/animal/dia, RVC de 60:40 (Teste 2); e dieta para ganhos de 1200 g/animal/dia, RVC de 40:60 (Teste 3). Vinte e quatro novilhas foram usadas por teste, oito de cada grupo genético. Cada teste compreendeu três etapas: a) desempenho, de 90 dias, em que foram determinados o consumo de matéria seca e o ganho em peso diário dos animais; b) digestibilidade aparente das dietas e balanço de nitrogênio dos animais; e c) taxas de passagem da fase líquida da digesta. Os animais de CA, NE e CANE tiveram desempenho semelhante, dentro de cada dieta, para todas as variáveis analisadas.
\end{abstract}

Palavras-chave: balanço de nitrogênio, bovinos, desempenho, digestibilidade, taxa de passagem, valor nutritivo da dieta

\section{Efficiency of Nutrient Utilization by Canchim, Nellore and Crossbreed Canchim- Nellore Breed Heifers}

\begin{abstract}
The objective of this work was to study the efficiency of nutrient utilization by Canchim (CA), Nellore (NE) and crossbreed 1/2 Canchim + 1/2 Nelore (CANE) growing heifers, in three diets: maintenance, forage:concentrate ratio (RFC) of 75:25 (test 1), diet for weight gains up to $700 \mathrm{~g} / \mathrm{animal} / \mathrm{day}$, RFC of 60:40 (test 2) and diet for weight gains up to $1200 \mathrm{~g} / \mathrm{animal} / \mathrm{day}$, RFC of 40:60 (test 3). Twenty-four heifers were used in each test, eight of each genetic group. Each test had by three phases: a) performance, of 90 days, where the dry matter intake and daily weight gains were determined; b) coefficients of apparent digestibility and nitrogen balance of animals; and c) liquid phase digesta passage rates. The heifers from CA, NE and CANE showed similar results, within each diet, for all analyzed variables.
\end{abstract}

Key Words: nitrogen balance, cattle, performance, digestibility, passage rate, nutritive value of diet

\section{Introdução}

A produção animal eficiente é dependente da utilização racional dos recursos genéticos e ambientais e da interação desses. Assim, a pesquisa deve ser dirigida para melhorar a eficiência e maximizar a produção, considerando o binômio genótipo-ambiente. Portanto, é necessário o conhecimento das características fisiológicas das várias raças e dos tipos de bovinos, uma vez que o potencial para a produção animal depende da capacidade de cada tipo de animal em utilizar eficientemente os recursos do ambiente que o cerca.

A alimentação, tendo em vista os seus efeitos sobre o custo de produção, é um dos fatores do ambiente que influi na produção de bovinos que merece destaque. As pesquisas nesta área realizadas no Brasil, com base em exigências de nutrientes provenientes de tabelas americanas ou européias, têm mostrado resultados diferentes dos esperados, principalmente para os zebuínos (SAMPAIO et al., 1998).

A interação genótipo $\mathrm{x}$ ambiente ocorre quando os grupos genéticos respondem diferentemente às variações do ambiente. A interação entre grupo genético e dieta ficou demonstrada no trabalho de OLIVEIRA et al. (1994), quando compararam taurinos, zebuínos e seus cruzamentos, e em experimentos que estudaram a eficiência de utilização de nutrientes, por meio dos índices de desempenho e dos coeficientes de digestibilidade (VALADARES FILHO et al., 1985; GONÇALVES et al., 1991). Entretanto, considerando apenas taurinos, não foram detectadas diferenças no aproveitamento dos nutrientes, quando fornecidos com níveis iguais de gordura na dieta (BRUNGART, 1972), e na interação de raça e dieta para ganho em peso, conversão alimentar, rendimento de carcaça e peso ao abate (PRICE

\footnotetext{
1 Pesquisador da Embrapa Pecuária Sudeste, São Carlos, SP.

2 Bolsista do CNPq.

3 Professor da UNIP/Ribeirão Preto, SP.
} 
et al., 1984). Contudo, WRIGTH et al. (1994) mostraram interação de genótipo e nutrição para diferentes medidas de eficiência em animais taurinos cruzados, como peso da vaca, produção e composição do leite, ingestão de matéria orgânica, peso do bezerro à desmama, entre outros.

No Brasil, alguns trabalhos têm mostrado a superioridade dos animais cruzados em relação às raças puras quanto à eficiência de utilização de nutrientes. HADDAD (1978) observou que a raça Canchim foi superior $(\mathrm{P}<0,05)$ à Charolesa quanto à digestibilidade da matéria seca $(44,7$ e $39,6 \%)$, fibra bruta $(38,0$ e $33,3 \%)$, extrato etéreo $(36,0$ e $27,6 \%)$ e celulose $(39,9$ e $32,2 \%)$. MANZANO et al. (1987), trabalhando com dietas de baixo valor nutritivo com relação concentrado:volumoso (30:70), mostraram que a digestibilidade da fibra bruta das raças Canchim e Nelore foi 30,6 e 31,9\%, ambas superiores $(\mathrm{P}<0,05)$ à do Holandês- Zebu (29,6\%); em dietas de médio valor nutritivo (50:50), o Holandês-Zebu, com 53,8\%, foi superior $(\mathrm{P}<0,05)$ ao Nelore, com $48 \%$, e semelhante ao Canchim, e em dietas com alto valor nutritivo (60:40) os três grupos genéticos foram semelhantes quanto à digestibilidade dos nutrientes estudados.

O presente trabalho teve por objetivo estudar a interação grupos genéticos $\mathrm{x}$ dieta utilizando-se novilhas das raças Canchim e Nelore e cruzadas CanchimNelore e três dietas com diferentes níveis nutricionais.

\section{Material e Métodos}

O trabalho foi desenvolvido no período de janeiro de 1988 a setembro 1989 na Embrapa Pecuária Sudeste, em São Carlos, SP, utilizando-se 72 novilhas, sendo 24 de cada grupo genético, Canchim (CA), Nelore (NE) e 1/2 Canchim + 1/2 Nelore (CANE), e três dietas (testes), cujas composições estão na Tabela l. Em cada teste foram utilizadas 24 fêmeas, oito de cada grupo genético, cujos pesos, em kg e idades

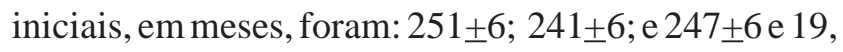
19 e 18 (teste 1 ); $298 \pm 6 ; 220 \pm 6$; e $261 \pm 6$ e 20,21 e 20 (teste 2); e 308 \pm 6 ; 236 \pm 6 ; e 315 \pm 6 e 19, 20 e 19 meses (teste 3), para CA, NE e CANE, respectivamente. O período experimental foi de janeiro a junho de 1988, julho a dezembro e de abril a setembro de 1989, para os testes 1,2 e 3 , respectivamente.

As dietas experimentais foram balanceadas, segundo o NATIONAL RESEARCH COUNCIL NRC (1984), para mantença dos animais no teste 1, ganhos de $700 \mathrm{~g} / \mathrm{animal} / \mathrm{dia}$ no teste 2 e de $1200 \mathrm{~g} /$ animal/dia no teste 3 . No teste 1 , o concentrado era constituído de uréia e farelo de trigo. Nos testes 2 e 3 os concentrados foram constituídos de farelo de soja, farelo de trigo, milho em grão e uréia e o volumoso foi a cana-de-açúcar, variedade SP 70.1423, que era cortada diariamente e picada antes de cada refeição (8 e $16 \mathrm{~h})$. Os animais ainda receberam $60 \mathrm{~g} /$ dia de mistura mineral. Os testes foram antecedidos por um período de 30 dias de adaptação dos animais e divididos em três etapas: a) desempenho, de noventa dias, em que se determinaram os consumos diários e ganhos em peso individual, com pesagens a cada duas semanas, antecedidas de jejum absoluto de 16 horas, observado apenas na primeira e última pesagens; b) digestibilidade e balanço de nitrogênio, de 14 dias, sendo sete para adaptação às dietas completas (concentrado + volumoso) e sete para coleta das sobras de rações, fezes e urina utilizadas na determinação dos coeficientes de digestibilidade (CD) da matéria seca (MS), proteína bruta (PB), energia bruta (EB), fibra em detergente neutro (FDN), fibra em detergente ácido (FDA) e balanço de nitrogênio; e c) estimativa da taxa de passagem da fase líquida da digesta, durante quatro dias. Para determinação dos $\mathrm{CD}$, foi utilizado o método dos indicadores (óxido crômico), oferecendo-se $10 \mathrm{~g}$ / animal/dia durante os 14 dias, divididos nas duas refeições diárias. Foram coletados, no reto dos animais, cerca de $100 \mathrm{~g}$ de fezes durante cada refeição, que, posteriormente, foram colocados em congelador a $10+1^{\circ} \mathrm{C}$. Do total, após homogeneização e secagem, foram coletados $100 \mathrm{~g}$ para as análises químicas.

Para determinação do balanço de nitrogênio, a urina foi coletada por meio de sondas de Folley, calibre 20 e balão de $30 \mathrm{~mL}$, em baldes de 20 litros, contendo $100 \mathrm{~mL}$ de ácido clorídrico 37\% diluídos em $50 \mathrm{~mL}$ de água destilada, para manter o $\mathrm{pH}$ ao redor de 4,0. A urina foi pesada diariamente e cerca de $100 \mathrm{~mL} /$ animal foram colocados no congelador a $-10+1^{\circ} \mathrm{C}$, para serem analisados posteriormente.

Para estimar a taxa de passagem da fase líquida da digesta, foi utilizado como indicador o complexo cobaltoEDTA (UDÉN et al.,1982), oferecido em dose única ( $2 \mathrm{~g} /$ animal). As amostragens das fezes foram realizadas às $0,8,16,24,30,40,48,56,65,72,79$ e 90 horas após a dosagem. A taxa de passagem foi calculada com base no logaritmo natural da concentração do marcador excretado nas fezes (UDÉN et al., 1980).

Os animais foram confinados e mantidos individualmente em estábulo de alvenaria, com piso de cimento, sem cama, com bebedouro automático e cocho de cimento; o estábulo era dotado de cortinas que impediam a entrada de vento e chuva, proporcionando 
Rev. bras. zootec.

conforto aos animais durante os dias frios e chuvosos.

Alimentos, rações, sobras, fezes e urina foram analisados para se obter teor de nitrogênio (Association of Official Agricultural Chemists - AOAC, 1980) e energia bruta, por bomba calorimétrica de PARR; FDN e FDA, de acordo com GOERING e VAN SOEST (1970); e cromo e cobalto, por absorção atômica.

Os caracteres analisados foram ganho diário em peso vivo, consumo diário de matéria seca (MS), consumo de MS por quilograma de peso metabólico, conversão alimentar, digestibilidade da matéria seca, da proteína bruta, da energia bruta, da fibra em detergente neutro e da fibra em detergente ácido, $\mathrm{N}$ ingerido, $\mathrm{N}$ retido, $\mathrm{N}$ retido por peso metabólico, relação $\mathrm{N}$ retido: $\mathrm{N}$ ingerido e taxa de passagem da fase líquida da digesta. Os dados foram analisados por meio do procedimento GLM do SAS (SAS, 1993), conforme modelo abaixo:

$$
\begin{aligned}
& \text { yijk }=\mu+D_{i}+G(D)_{j(i)}+\beta\left(X_{i j k}-\bar{X}\right)+\varepsilon_{j k(i)} \\
& \text { em que }
\end{aligned}
$$

$\mathrm{y}_{\mathrm{ijk}} \quad=$ valor observado no k-ésimo animal do j-ésimo teste do i-ésimo grupo genético;

$$
\begin{array}{ll}
\mu & =\text { efeito médio; } \\
\mathrm{Di} & =\text { efeito principal da dieta; } \\
\mathrm{G}(\mathrm{D})_{\mathrm{j}(\mathrm{i})} & =\text { efeito do j-ésimo grupo genético }
\end{array}
$$
dentro do i-ésimo teste;

$\beta\left(X_{i j k}-\bar{X}\right)=$ coeficiente de regressão linear $(\beta)$ entre $\mathrm{y}_{\mathrm{ijk}}$ e $X_{\mathrm{ijk}}$ (peso do k-ésimo animal da j-ésimo teste do i-ésimo grupo genético); $\mathrm{X}$ é a média dos valores de X;

$\varepsilon_{\mathrm{jk}(\mathrm{i})}=$ efeito aleatório, supostamente com distribuição normal, média zero e variância $\sigma^{2}, \varepsilon_{j k(i)}$ $\mathrm{N}\left(0, \sigma^{2}\right)$.
O efeito de dieta foi colocado no modelo apenas para propósito de partição de somas de quadrados e ajuste de graus de liberdade (GL); esse efeito está confundido com época de realização dos testes e animais. No modelo proposto, testa-se o desdobramento de G(D)j(i), com maior precisão, pois utiliza-se maior número de GL para o resíduo $(\mathrm{GL}=63)$, ao passo que na realização de três análises isoladas, o efeito de grupo genético é testado com apenas 21 GL para o resíduo.

\section{Resultados e Discussão}

Os animais dos três grupos genéticos tiveram desempenho semelhante em todos os caracteres estudados dentro de cada teste.

\section{Consumo, ganho e conversão alimentar}

No teste 1 (Tabela 2), o ganho em peso obtido para CA $(381 \pm 31 \mathrm{~g} / \mathrm{animal} / \mathrm{dia})$, CANE $(282 \pm 31 \mathrm{~g} /$ animal/dia) e NE $(248 \pm 31 \mathrm{~g} / \mathrm{animal} / \mathrm{dia})$ não diferiu estatisticamente, o mesmo ocorrendo com o consumo de CA $\left(78,0+1,9 \mathrm{~g} \mathrm{MS} / \mathrm{kg}^{0,75}\right)$, CANE $(73,9+1,9$ $\left.\mathrm{gMS} / \mathrm{kg}^{0,75}\right)$ e $\mathrm{NE}\left(65,8+1,9 \mathrm{gMS} / \mathrm{kg}^{0,75}\right)$. É importante ressaltar que os animais deste teste ingeriram de 4,2 a 5,2 kg de MS/dia, correspondendo, em média, a 70\% do consumo mínimo de 6,4 kgMS/animal/dia recomendado pelo NRC (1984) para ganhos em peso de até $300 \mathrm{~g} / \mathrm{animal} / \mathrm{dia}$. A conversão alimentar foi de 15,5 a $18,1 \mathrm{~kg}$ de MS ingerida/kg de peso vivo, nos grupos genéticos em estudo. O consumo em quilograma de matéria seca, em relação a $100 \mathrm{~kg}$ de peso vivo (\%PV), obtido no presente estudo foi de 1,8 para CA

\begin{tabular}{|c|c|c|c|c|c|c|c|c|c|}
\hline \multirow[b]{2}{*}{ Item } & \multicolumn{3}{|c|}{$\begin{array}{c}\text { Teste } 1 \\
\text { Test } 1\end{array}$} & \multicolumn{3}{|c|}{$\begin{array}{l}\text { Teste } 2 \\
\text { Test } 2\end{array}$} & \multicolumn{2}{|c|}{$\begin{array}{c}\text { Teste } 3 \\
\text { Test } 3\end{array}$} & \multirow[b]{2}{*}{$\mathrm{Ra}$} \\
\hline & Co & $\mathrm{Ca}$ & $\mathrm{Ra}$ & $\mathrm{Co}$ & $\mathrm{Ca}$ & $\mathrm{Ra}$ & Co & $\mathrm{Ca}$ & \\
\hline $\begin{array}{l}\text { Matéria seca } \\
\text { Drv matter }\end{array}$ & 90,54 & 29,94 & 45,09 & 89,83 & 30,46 & 54,20 & 94,53 & 31,86 & 69,46 \\
\hline $\begin{array}{l}\text { Proteína bruta } \\
\text { Crude protein }\end{array}$ & 22,88 & 1,33 & 6,71 & 24,23 & 2,15 & 10,98 & 24,38 & 1,60 & 15,26 \\
\hline $\begin{array}{l}\text { Energia bruta }(\mathrm{kcal} / \mathrm{g}) \\
\text { Gross energy }\end{array}$ & 3,94 & 3,91 & 3,92 & 4,18 & 3,88 & 4,00 & 4,23 & 4,07 & 4,17 \\
\hline $\begin{array}{l}\text { Fibra em detergente neutro } \\
\text { Neutral detergentfiber }\end{array}$ & 58,28 & 50,45 & 52,40 & 22,00 & 52,68 & 40,40 & 22,46 & 46,33 & 32,00 \\
\hline $\begin{array}{l}\text { Fibra em detergente ácido } \\
\text { Acid detergent fiber }\end{array}$ & 11,84 & 31,93 & 26,90 & 7,12 & 29,37 & 20,47 & 6,47 & 28,15 & 15,14 \\
\hline $\begin{array}{l}\text { Volumoso:concentado } \\
\text { Forage:concentrate }\end{array}$ & & & $75: 25$ & & & $60: 40$ & & & 40:60 \\
\hline
\end{tabular}
e CANE e 1,6 para NE. No teste 2, o ganho diário em peso para CANE $(796+31 \mathrm{~g} / \mathrm{animal} / \mathrm{dia}), \mathrm{CA}(765+31$

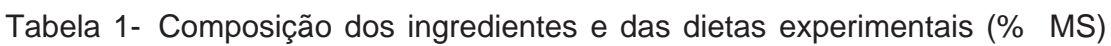
Table 1- Composition of ingredients and experimental diets (\% DM) 
MANZANO et al.

Tabela 2- Médias do peso final, ganho diário em peso, consumo de matéria seca e conversão alimentar, por teste, para animais Canchim (CA), Canchim-Nelore (CANE) e Nelore (NE)

Table 2- Means of final weigh daily weight gain, dry matter intake, and feed:gain ratio per test, for Canchim (CA), Canchim-Nellore (CANE) and Nellore (NE) animals

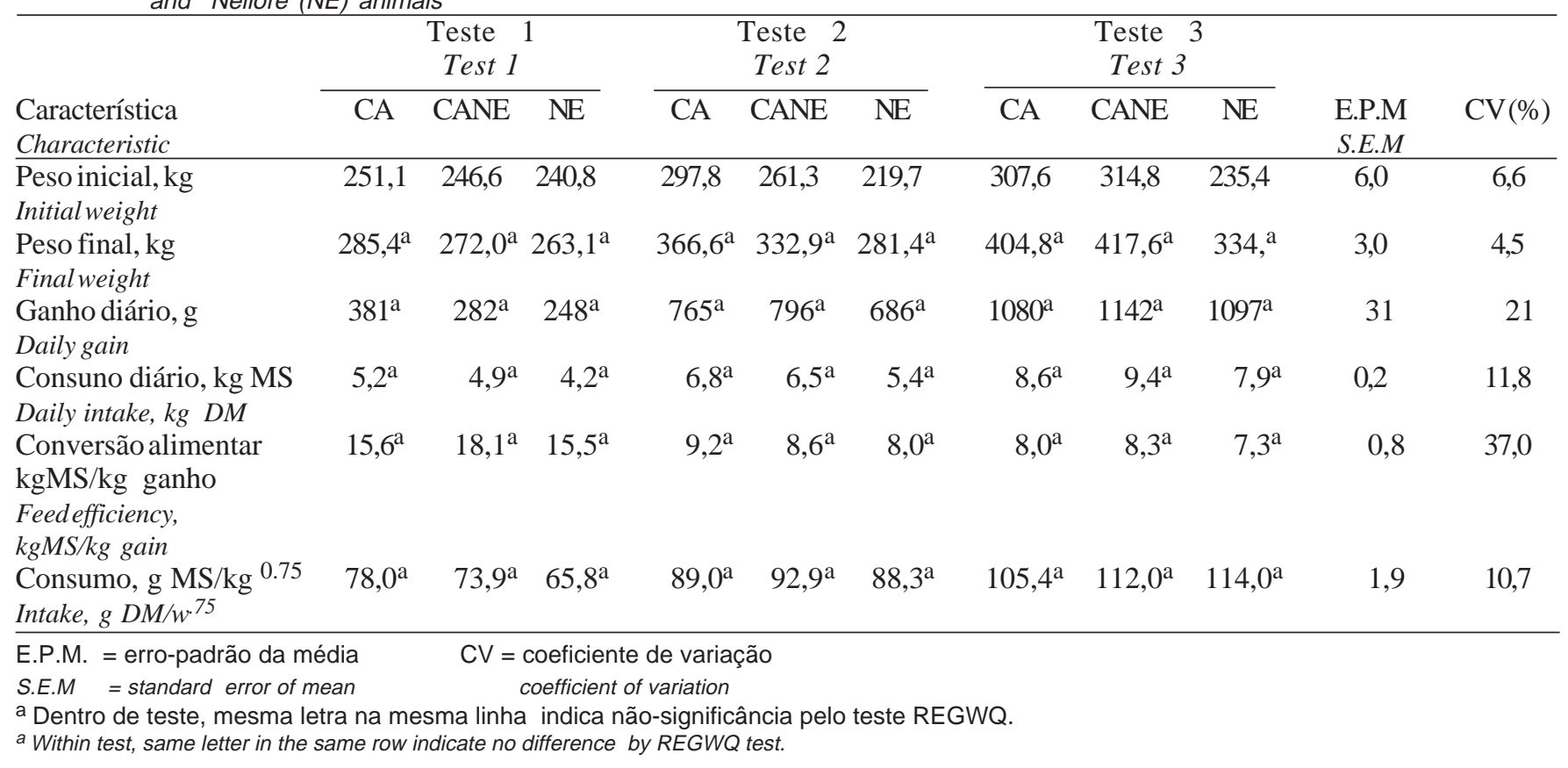

$\mathrm{g} / \mathrm{animal} / \mathrm{dia})$ e NE $(686 \pm 31 \mathrm{~g} / \mathrm{animal} / \mathrm{dia})$, enquanto foi para CANE, CA e NE obteve-se consumo de, respectivamente $(92,9 \pm 1,9 ; 89,0 \pm 1,9 ;$ e $88,3 \pm 1,9 \mathrm{~g}$ de $\mathrm{MS} / \mathrm{kg}^{0,75}$ ), não apresentando diferenças estatísticas entre grupos genéticos para estes dois caracteres. Estes resultados são semelhantes aos obtidos com Nelore $\left(89,1 \mathrm{~g} \mathrm{MS} / \mathrm{kg}^{0,75}\right)$ e inferiores aos de F1 Nelore-Chianina (105,1 g de MS/kg $\left.{ }^{0,75}\right)$, em dietas com 30 e $50 \%$ de concentrado na MS (OLIVEIRA et al., 1994). O menor consumo alimentar em animais $\mathrm{NE}$, associado ao seu menor potencial de ganho em peso, pode indicar menores exigências nutricionais em relação aos animais cruzados (GALVÃO, 1991). Os dados de consumo diário dos animais foram 5,4 a $6,8 \mathrm{~kg}$ de MS, que estão próximos aos recomendados pelo NRC (1984), 6,6 kg de MS/animal/dia para ganhos de $700 \mathrm{~g} /$ animal/dia. Os resultados de conversão alimentar para NE $(8,0 \pm 0,8 \mathrm{~kg}$ MS ingerida $/ \mathrm{kg}$ ganho de peso vivo), CANE $(8,6 \pm 0,8 \mathrm{~kg} / \mathrm{kg})$ e CA $(9,2 \pm 0,8 \mathrm{~kg} / \mathrm{kg})$, embora numericamente diferentes, não apresentaram diferenças significativas. O consumo (kg de MS), em porcentagem de PV obtido no presente estudo, foi 1,8; 1,8; e 1,6 para CA, CANE e NE, respectivamente. No teste 3 , o ganho em peso diário de $1.080 \pm 31$, $1.142 \pm 31$ e $1.097 \pm 31 \mathrm{~g} /$ animal e o consumo diário de 7,9 a 9,4 kg de MS/animal proporcionaram conversão alimentar de $8,0 \pm 0,8 ; 8,3 \pm 0,8 ;$ e $7,3 \pm 0,8 \mathrm{~kg} / \mathrm{kg}$, para CA, CANE e NE, respectivamente. Os dados de consumo também estão próximos aos recomendados pelo NRC (1984), indicando que, para ganhos diários próximos a $1.200 \mathrm{~g} / \mathrm{animal}$, deve haver consumo de MS de 8,3 kg/animal. O consumo por peso metabólico foi de $105,4 \pm 1,9 ; 112,0 \pm 1,9$; e 114,0 $\pm 1,9 \mathrm{~g} \mathrm{MS} /$ $\mathrm{kg}^{0,75}$, para CA, CANE e NE, respectivamente, resultados que discordam dos obtidos por OLIVEIRA et al. (1994), os quais mostraram que a ingestão no NE foi inferior à do $1 / 2$ Nelore $+1 / 2$ Chianina. O consumo (kg de MS) em \%PV foi 2,1; 2,2; e 2,4, para CA, CANE e NE, respectivamente.

Digestibilidade e balanço de nitrogênio

As médias dos CD aparente da MS, PB, EB, FDN e FDA dos três grupos genéticos foram semelhantes em cada dieta experimental (Tabela 3 ). No teste 1, apesar de não ter havido significância, os coeficientes estudados foram ligeiramente superiores para os animais CA, quando comparados aos de NE e CANE, havendo uniformidade entre os dois últimos grupos. Estes resultados contrariam os obtidos por MOORE et al. (1975) e MANZANO et al. (1987), os quais relataram a superioridade do zebu na digestão da MS, energia bruta e fibra bruta de dietas de baixo valor nutritivo. Entretanto, confirmam os de WARWICK e COBB (1975), citado por Infanzón (1978), e GONÇALVES et al. (1991), que, comparando raças de bovinos Bos taurus com Bos indicus do tipo carne e seus cruzamentos, verifica- 
Rev. bras. zootec.

Tabela 3 - Médias de coeficientes de digestibilidade aparente da matéria seca, proteína bruta, energia bruta, fibra em detergente neutro e fibra em detergente ácido, para animais Canchim (CA), Canchim-Nelore (CANE) e Nelore (NE)

Table 3 - Means of apparent digestibility coefficient of dry matter, crude protein, gross energy, neutral detergent fiber and acid detergent fiber for Canchim (CA), Canchim-Nellore (CANE) and Nellore (NE) animals

\begin{tabular}{|c|c|c|c|c|c|c|c|c|c|c|c|}
\hline \multirow[b]{2}{*}{$\begin{array}{l}\text { Coeficiente de } \\
\text { digestibilidade }(\%) \\
\text { Coefficient of digestibility }\end{array}$} & \multicolumn{3}{|c|}{$\begin{array}{c}\text { Teste } 1 \\
\text { Test } 1 \\
\end{array}$} & \multicolumn{3}{|c|}{$\begin{array}{c}\text { Teste } 2 \\
\text { Test } 2\end{array}$} & \multicolumn{3}{|c|}{$\begin{array}{c}\text { Teste } 3 \\
\text { Test } 3 \\
\end{array}$} & \multirow[b]{2}{*}{$\begin{array}{l}\text { E.P.M } \\
\text { S.E.M }\end{array}$} & \multirow[b]{2}{*}{$\mathrm{CV}(\%)$} \\
\hline & CA & CANE & $\mathrm{NE}$ & CA & CANE & $\mathrm{NE}$ & CA & CANE & $\mathrm{NE}$ & & \\
\hline $\begin{array}{l}\text { Matéria seca } \\
\text { Dry matter }\end{array}$ & $52,3^{\mathrm{a}}$ & $50,5^{\mathrm{a}}$ & $50,9^{\mathrm{a}}$ & $71,2^{\mathrm{a}}$ & $66,6^{\mathrm{a}}$ & $65,6^{\mathrm{a}}$ & $73,6^{\mathrm{a}}$ & $75,0^{\mathrm{a}}$ & $75,5^{\mathrm{a}}$ & 0,9 & 6,6 \\
\hline $\begin{array}{l}\text { Proteína bruta } \\
\text { Crude protein }\end{array}$ & $47,4^{\mathrm{a}}$ & $46,5^{\mathrm{a}}$ & $45,9^{\mathrm{a}}$ & $66,2^{\mathrm{a}}$ & $62,6^{\mathrm{a}}$ & $61,8^{\mathrm{a}}$ & $72,5^{\mathrm{a}}$ & $73,2^{\mathrm{a}}$ & $73,4^{\mathrm{a}}$ & 0,9 & 7,9 \\
\hline $\begin{array}{l}\text { Energia bruta } \\
\text { Gross energy }\end{array}$ & $52,4^{\mathrm{a}}$ & $50,7^{\mathrm{a}}$ & $51,2^{\mathrm{a}}$ & $73,6^{\mathrm{a}}$ & $69,4^{\mathrm{a}}$ & $68,9^{\mathrm{a}}$ & $70,9^{a}$ & $73,8^{\mathrm{a}}$ & $73,5^{\mathrm{a}}$ & 0,9 & 6,6 \\
\hline $\begin{array}{l}\text { Fibra em detergente } \\
\text { neutro }\end{array}$ & $22,9^{\mathrm{a}}$ & $21,3^{\mathrm{a}}$ & $20,9^{\mathrm{a}}$ & $63,2^{\mathrm{a}}$ & $57,3^{\mathrm{a}}$ & $56,6^{\mathrm{a}}$ & $52,6^{\mathrm{a}}$ & $57,4^{\mathrm{a}}$ & $56,4^{\mathrm{a}}$ & 1,4 & 14,7 \\
\hline $\begin{array}{l}\text { Neutral detergentfiber } \\
\text { Fibra em detergente } \\
\text { ácido } \\
\text { Acid detergentfiber }\end{array}$ & $16,3^{\mathrm{a}}$ & $12,7^{\mathrm{a}}$ & $15,0^{\mathrm{a}}$ & $46,5^{\mathrm{a}}$ & $41,0^{\mathrm{a}}$ & $41,2^{\mathrm{a}}$ & $45,0^{\mathrm{a}}$ & $46,3^{\mathrm{a}}$ & $43,5^{\mathrm{a}}$ & 1,7 & 25,1 \\
\hline
\end{tabular}

E.P.M. = erro-padrão da média; CV = coeficiente de variação

S.E.M. = standard error of mean coefficient of variation

a Dentro de teste, mesma letra na mesma linha indica não-significância pelo teste REGWQ.

a Within test, same letter in the same row indicate no difference by REGWQ test.

ram que as diferenças foram mínimas entre essas espécies. Contudo, a literatura sugere que estas diferenças existem e podem estar associadas às condições de ambiente (VERCOE e FRICH, 1970) e/ou às características das dietas utilizadas (MOORE et al., 1975). O consumo em MS/animal/dia nesse período foi $4,9 \pm 0,3 ; 4,5 \pm 0,3$; e $3,7 \pm 0,3 \mathrm{~kg}$ para CA, CANE e NE, respectivamente. No teste 2, os resultados mantiveram o mesmo comportamento, ou seja, CD mais elevados dos animais CA em relação ao dos animais CANE e NE, apesar de não ser significativamente diferente. Estes resultados confirmam os obtidos por VALADARES FILHO et al. (1985), LORENZONI et al. (1986) e MANZANO et al. (1987), os quais não encontraram diferenças significativas nos CD de taurinos, zebuínos e seus cruzamentos, utilizando dietas cujo teor de concentrados nas rações variou de 40 a $60 \%$. O consumo de MS/animal/dia nesse período foi de $8,2 \pm 0,3 ; 7,4 \pm 0,3$ e $6,3 \pm 0,3 \mathrm{~kg}$ para CA, CANE e NE, respectivamente. Quanto ao teste 3, verificou-se tendência de melhor CD dos animais CANE e NE sobre os CA, confirmando os resultados obtidos porLORENZONI et al. (1986) e MANZANO et al. (1987) com dietas contendo de $60 \%$ de concentrado. O consumo em MS/animal/dia nesse período foi $9,1 \pm 0,3 ; 9,1 \pm 0,3$; e $6,9 \pm 0,3 \mathrm{~kg}$ para CA, CANE e NE, respectivamente.

Quanto ao balanço de nitrogênio (Tabela 4), não houve diferenças entre os grupos genéticos nos testes. No teste 1 , o $\mathrm{NE}\left(162+36 \mathrm{mg}\right.$ de $\left.\mathrm{N} / \mathrm{kg}^{0,75}\right)$ mostrou tendência de reter menos nitrogênio que o CANE $\left(221+36 \mathrm{mg}\right.$ de $\left.\mathrm{N} / \mathrm{kg}^{0,75}\right)$ e o CA $(239 \pm 36 \mathrm{mg}$ de $\mathrm{N} / \mathrm{kg}^{0,75}$ ), confirmando os resultados de MANZANO et al. (1987), em animais das raças CA e NE e cruzados Holandês x Zebu. Quanto ao teste 2, os resultados de retenção de nitrogênio de $636 \pm 36$; $496 \pm 36$ e $468 \pm 36 \mathrm{mg} / \mathrm{kg}^{0,75}$ para CA, CANE e NE, respectivamente, revelaram tendência de superioridade do CA sobre os demais grupos. Resultados semelhantes foram encontrados por MANZANO et al. (1987), 571, 705 e $706 \mathrm{mg}$ de $\mathrm{N} / \mathrm{kg}^{0,75}$, para animais NE, CA e cruzados Holandês x Zebu com dietas constituídas de $50 \%$ de concentrado. No teste 3 , embora o consumo de nitrogênio dos animais CA e CANE $(222,1 \pm 3,2 \mathrm{gN} / \mathrm{animal} / \mathrm{dia})$ tenha sido superior ao dos animais $\mathrm{NE}(167,4 \pm 3,2 \mathrm{gN} / \mathrm{animal} / \mathrm{dia})$, a relação $\mathrm{N}$ retido: $\mathrm{N}$ ingerido nos três grupos genéticos foi semelhante $(35,8 \pm 1,9 ; 35,6 \pm 1,9 ;$ e $33,7 \pm 1,9 \%)$. Estes resultados estão de acordo com os de mestiços HolandêsZebu, porém superiores aos do NE e CA em dietas com $60 \%$ de concentrado (MANZANO et al., 1987).

\section{Taxas de passagem}

Considerando as dietas, não houve diferenças entre os grupos genéticos quanto às taxas de passagem da fase líquida da digesta (Tabela 5). No teste 1, estes valores foram $5,0 \pm 0,4 ; 5,0 \pm 0,4 ;$ e $4,7 \pm 0,4 \%$ /hora, para CA, CANE e NE, respectivamente. Taxas de passagem mais altas refletem reciclagem alimentar mais rápida, com conseqüente esvaziamento do sistema 
Tabela 4 - Ingestão, excreção e balanço de nitrogênio para animais Canchim (CA), Canchim-Nelore (CANE) e Nelore (NE) Table 4 - Intake, excretion and nitrogen balance for Canchim (CA), Canchim-Nellore (CANE) and Nellore (NE) animals

\begin{tabular}{|c|c|c|c|c|c|c|c|c|c|c|c|}
\hline \multirow[b]{2}{*}{$\begin{array}{l}\text { Característica } \\
\text { Characteristic }\end{array}$} & \multicolumn{3}{|c|}{$\begin{array}{c}\text { Teste } 1 \\
\text { Test } 1\end{array}$} & \multicolumn{3}{|c|}{$\begin{array}{c}\text { Teste } 2 \\
\text { Test } 2 \\
\end{array}$} & \multicolumn{3}{|c|}{$\begin{array}{l}\text { Teste } 3 \\
\text { Test } 3 \\
\end{array}$} & \multirow[b]{2}{*}{$\begin{array}{l}\text { E.P.M } \\
\text { S.E.M }\end{array}$} & \multirow[b]{2}{*}{$\mathrm{CV}(\%)$} \\
\hline & $\mathrm{CA}$ & CANE & $\mathrm{NE}$ & $\mathrm{CA}$ & CANE & $\mathrm{NE}$ & $\mathrm{CA}$ & CANE & $\mathrm{NE}$ & & \\
\hline $\begin{array}{l}\mathrm{N} \text { ingerido, g/dia } \\
N \text { intake, g/day }\end{array}$ & $51,4^{\mathrm{a}}$ & $47,4^{\mathrm{a}}$ & $39,3^{\mathrm{a}}$ & $143,8^{\mathrm{a}}$ & $130,1^{\mathrm{a}}$ & $111,2^{\mathrm{a}}$ & $222,1^{\mathrm{a}}$ & $222,1^{\mathrm{a}}$ & $167,4^{\mathrm{a}}$ & 3,2 & 12,8 \\
\hline $\begin{array}{l}\mathrm{N} \text { fecal, g/dia } \\
\text { Fecal } N, \text { g/day }\end{array}$ & $21,9^{\mathrm{a}}$ & $19,1 \mathrm{a}$ & $17,2^{\mathrm{a}}$ & $43,2^{\mathrm{a}}$ & $46,1^{\mathrm{a}}$ & $39,8^{\mathrm{a}}$ & $58,3^{\mathrm{a}}$ & $52,0^{\mathrm{a}}$ & $41,9^{\mathrm{a}}$ & 1,4 & 12,8 \\
\hline $\begin{array}{l}\text { N urinário, g/dia } \\
\text { Urinary } N, \text { g/day }\end{array}$ & $13,4^{\mathrm{a}}$ & $14,1^{\mathrm{a}}$ & $11,8^{\mathrm{a}}$ & $50,5^{\mathrm{a}}$ & $49,8^{\mathrm{a}}$ & $42,5^{\mathrm{a}}$ & $84,4^{\mathrm{a}}$ & $91,1^{\mathrm{a}}$ & $69,0 \mathrm{a}$ & 1,3 & 13,5 \\
\hline $\begin{array}{l}\mathrm{N} \text { retido, } \mathrm{g} / \mathrm{dia} \\
\text { Retained } N, \text { g/day }\end{array}$ & $16,1^{\mathrm{a}}$ & $14,2^{\mathrm{a}}$ & $10,3^{\mathrm{a}}$ & $50,1^{\mathrm{a}}$ & $34,2^{\mathrm{a}}$ & $28,9^{\mathrm{a}}$ & $79,5^{\mathrm{a}}$ & $79,1^{\mathrm{a}}$ & $56,5^{\mathrm{a}}$ & 2,8 & 32,8 \\
\hline $\begin{array}{l}\mathrm{N} \text { retido } / \mathrm{kg}^{0}, 75, \mathrm{mg} / \mathrm{dia} \\
\text { Retained } \mathrm{N} / \mathrm{w}^{.75}, \mathrm{mg} / \text { day }\end{array}$ & $239^{a}$ & $221^{\mathrm{a}}$ & $162^{\mathrm{a}}$ & $636^{\mathrm{a}}$ & $496^{\mathrm{a}}$ & $468^{a}$ & $947^{\mathrm{a}}$ & $915^{\mathrm{a}}$ & $828^{a}$ & 36 & 32 \\
\hline $\begin{array}{l}\mathrm{N} \text { retido: } \mathrm{N} \text { ingerido, } \% \\
\text { Retained } N: N \text { intake, } \%\end{array}$ & $31,3^{\mathrm{a}}$ & $29,9^{\mathrm{a}}$ & $26,3^{\mathrm{a}}$ & $41,3^{\mathrm{a}}$ & $26,3^{a}$ & $30,0^{\mathrm{a}}$ & $35,8^{a}$ & $35,6^{\mathrm{a}}$ & $33,7^{\mathrm{a}}$ & 1,9 & 29,7 \\
\hline
\end{tabular}

\begin{tabular}{|c|c|c|c|c|c|}
\hline $\begin{array}{l}\text { Teste } \\
\text { Test }\end{array}$ & $\begin{array}{l}\text { Canchim } \\
\text { Canchim }\end{array}$ & $\begin{array}{l}\text { Canchim-Nelore } \\
\text { Canchim-Nellore }\end{array}$ & $\begin{array}{l}\text { Nelore } \\
\text { Nellore }\end{array}$ & E.P.M. & $\mathrm{CV}(\%)$ \\
\hline 1 & $5,0^{\mathrm{a}}$ & $5,0^{\mathrm{a}}$ & $4,7^{\mathrm{a}}$ & 0,4 & 10,0 \\
\hline 2 & $7,2^{\mathrm{a}}$ & $6,5^{\mathrm{a}}$ & $6,9^{\mathrm{a}}$ & 0,6 & 28,7 \\
\hline 3 & $5,5^{\mathrm{a}}$ & $5,9^{\mathrm{a}}$ & $5,9^{\mathrm{a}}$ & 0,4 & 10,3 \\
\hline
\end{tabular}

digestivo, permitindo maior consumo (OWENS e GOETSCH, 1986). Os valores das taxas de passagem obtidos neste teste foram cerca de $50 \%$ inferiores aos obtidos por POORE et al. (1987), com dietas contendo três níveis de concentrado, e aos de GOMES et al. (1994), em estudos de características físico-químicas de fenos e palha; provavelmente a diferença encontrada se deve ao tamanho de partícula dos alimentos fornecidos, principalmente do volumoso, pois menor partícula resulta em maior taxa de passagem (FAICHNEY, 1986). No teste 2 , as taxas de passagem foram $7,2 \pm 0,6 ; 6,5 \pm 0,6$; e 6,9+0,6\%/hora, para CA, CANE e NE, respectivamente; a maior taxa de passagem do CA não proporcionou maior consumo alimentar, como observado no teste 1 e no trabalho de OWENS e GOETSCH (1986). No teste 3, a taxa de passagem do NE e CANE $(5,9 \pm 0,4 \%$ /hora) foi ligeiramente superior à do $\mathrm{CA}(5,6 \pm 0,4 \% /$ hora $)$, refletindo em maior consumo/peso metabólico destes grupos genéticos em relação aos animais Canchim.

\section{Conclusões}

Os animais da raça Nelore tiveram desempenho semelhante aos animais Canchim e 1/2 Canchim + 1/2 Nelore, em dieta que continham relação concentrado:volumoso de 25:75, 40:60 e 60:40. 


\section{Referências Bibliográficas}

ASSOCIATION OF OFFICIAL AGRICULTURAL CHEMISTS - AOAC. 1980. Official methods of analysis of the Association of Analytical Chemists. Washington, DC. $1018 \mathrm{p}$.

BRUNGART, V. W. 1972. Efficiency and profit differencies of Angus, Charolais and Hereford cattle varying in size and growth; feed efficiency and total feed requirement during the feedlot phase to reach choice grade. Madison: University of Wisconsin (Research report, 2398)

FAICHNEY, G.J. 1986. The kinetics of particulate matter in the rumen. In: CONTROL OF DIGESTIN AND METABOLISM IN RUMINANTS, 1984, Banff. Proceedings... Alberta, Canada: Banff Cente. p.173-195.

GALVÃO, J.G. Estudo da eficiência nutritiva, características e composição física da carcaça de bovinos de três grupos raciais abatidos em três estágios de maturidade. Viçosa, MG, UFV, 1991. 81p. Dissertação (Mestrado em Zootecnia) - Universidade Federal de Viçosa, 1991.

GOERING, H.K., VAN SOEST, J. 1970. Forage analyses. (S.1.): USDA. p.6-7. (Agric. Handbook, n.379).

GOMES, B.V. de, QUEIROZ, A.C., FONTES, A.A. et al. 1994. Estudo das características físico-químicas de fenos e palha. I. Efeitos sobre ingestão, digestibilidade aparente e taxa de passagem da matéria seca, pH e concentração de amônia ruminal. Rev. Soc. Bras. Zootec., 23(3):352-365.

GONÇALVES, L.C., SILVA, J.F.C., ESTEVÃO, M.M. et al. 1991. Consumo e digestibilidade da matéria seca e da energia em zebuínos e taurinos, seus mestiços e bubalinos. $R$. Soc Bras. Zootec., 20(4):384-395.

HADDAD, C.M. Eficiência de utilização de nutrientes pelas raças Canchim e Charolês. Piracicaba, SP: ESALQ, 1978. 91p. Dissertação (Mestrado em Nutrição Animal e Pastagem) Escola Superior de Agricultura "Luiz de Queiroz" - USP, 1978.

INFANZÓN, R.R.V. Efeito da raça bovina sobre as exigências nutricionais. In: SIMPÓSIO SOBRE EXIGÊNCIAS NUTRICIONAIS E AVALIAÇÃO DE ALIMENTOS PARA RUMINANTES NO BRASIL, 1978, Coronel Pacheco, MG. Anais... Coronel Pacheco: EMBRAPA-CNPGL, 1978. p.21-32.

LORENZONI,W.R., CAMPOS, J., GARCIA, J.A. et al. 1986. Ganho em peso, eficiência alimentar e qualidade da carcaça de novilhos búfalos, nelores, holandeses e mestiços HolandêsZebu. R. Soc. Bras. Zootec., 15(6):486-497.

MANZANO, A., NOVAES, N.J., ESTEVES, S.N. 1987. Eficiência de utilização de nutrientes pelas raças Nelore e Canchim e mestiços Holandês - Zebu. Pesq. Agropec. Bras., 22(8):873-880.

MOORE, R.L., ESSIG, H.W., SMITHSON, L.J. 1975. Influence of breeds of beef cattle on ration utilization. J. Anim. Sci., 41(2):203-207.

NATIONAL RESEARCH COUNCIL - NRC. 1984. Nutrient requirements of beef cattle. 6 ed. Washington D.C. 90p.

OLIVEIRA, M.A.T. Estimativa da digestibilidade através de indicadores e coleta total de fezes, consumo alimentar e biometria do trato gastrointestinal, em bovinos de cinco grupos genéticos. Viçosa, MG, UFV, 1991. 57p. Dissertação (Mestrado em Zootecnia) - Universidade Federal de Viçosa, 1991.
OLIVEIRA, M.A.T., FONTES, C.A.A., LANA, R.P. 1994. Consumo alimentar e digestibilidade de rações com dois níveis de concentrado em bovinos de cinco grupos genéticos. R. Soc. Bras. Zootec., 23(4):667-677.

OWENS, F.N., GOETSCH, G. 1986. Digesta forage and microbial protein synthesis. In: MILLIGAN, L.P., GROVUM, W.L., DOBSON, A. (Eds.) Control of digestion and metabolism in ruminants. New Jersey: Prentice-Hall. p.196-223.

POORE, M.H., MOORE, J.A., SWINGLE, R.S. 1987. Passage rates of individual diet components, neutral detergent fiber digestion and rumen $\mathrm{pH}$ in steers fed diets containing three levels of concentrate. J. Anim. Sci., 65:273 (Suppl.1).

PRICE, M.A., BUTSON, S., MAKARECHIAN, M. 1984. The influence of feed energy level on growth and carcass traits in bulls of two breed types. Can. J. Anim. Sci., 64(2):323-332.

SAMPAIO, A.A.M., BRITO, R.M., VIEIRA, P.F. et al. 1998. Efeito da suplementação protéica sobre crescimento, terminação e viabilidade econômica de bezerros mestiços Canchim confinados pós-desmama. R. Soc. Bras. Zootec., 27(4):823-831.

UDÉN, P., COLUCCI, P.E., VAN SOEST, P.J. 1980. Investigation of chromium, cerium and cobalt as markers in digesta: rate of passagem studies. J. Sci. Food. Agri., 31(6):625-632.

UDÉN, P., ROUNSAVILLE, T.R., WIGGANS, G.R. et al. 1982. The measurement of liquid and solid digesta retention in ruminants, equines and rabbits given timothy (Phleum pratense) hay. Br. J. Nutr., 48(2):329-339.

VALADARES FILHO, S.C., SILVA, J.F.C., LEÃO, M.I. et al. 1985. Digestão total e parcial da matéria seca e carboidratos em bovídeos alimentados com duas proporções de volumoso:concentrado (60:40 e 40:60). 2. Silagem de sorgo. R. Soc. Bras. Zootec., 14(5):587-598.

VERCOE, J.E., FRISCH, J.E. 1970. Digestibility and nitrogen metabolism in Brahman, Africander and Shorthorn x Hereford cattle fed lucerne hay. Proc. Aust. Soc. Anim. Prod., 8(1):131-137.

WRIGHT, I.A., JONES,J.R., MAXWELL,T.J. et al. 1994. The effect of genotype $\mathrm{x}$ environment interaction on biological efficiency in beef cows. Anim. Prod., 58(2):197-207.
Recebido em: 16/07/98 Aceito em: 12/04/99 